\title{
Preparation of Microcapsules Containing Grape Polyphenol with the Spray Drying Method Followed by the Layer-by-Layer Method
}

\author{
Yoshinari Taguchi, Shinji Arakawa, Natsukaze Saito, Masato Tanaka* \\ Graduate School of Science and Technology, Niigata University, Niigata, Japan \\ Email: ${ }^{*}$ tanaka@eng.niigata-u.ac.jp
}

Received 15 January 2015; accepted 6 February 2015; published 10 February 2015

Copyright (C) 2015 by authors and Scientific Research Publishing Inc.

This work is licensed under the Creative Commons Attribution International License (CC BY). http://creativecommons.org/licenses/by/4.0/

(c) (;) Open Access

\begin{abstract}
It was tried to prepare the microcapsules containing grape polyphenol with the spray drying method followed by the layer-by-layer method. As grape polyphenol was water soluble, the spray drying method was adopted to obtain the higher content. As the shell material of the first microcapsules prepared by the spray drying method, palmitic acid with the melting point of $60^{\circ} \mathrm{C}$ was adopted in order to prevent grape polyphenol from dissolution into water. As the shell material of the second microcapsules prepared by the layer-by-layer method, chitosan was used to coat the first microcapsules and to give the microcapsules alcohol resistance. In the experiment, the spray drying conditions such as the inlet temperature and the spraying pressure, the oil soluble surfactant species and the chitosan concentration were changed. The mean diameters of microcapsules could be controlled in the range from $5 \mu \mathrm{m}$ to $35 \mu \mathrm{m}$ by changing the spraying pressure and the inlet temperature. The yield of microcapsules and the microencapsulation efficiency over $50 \%$ could be obtained under the conditions of $P=1.0 \mathrm{kgf} / \mathrm{cm}^{2}$ and $T_{\text {in }}=100^{\circ} \mathrm{C}$. Furthermore, the microencapsulation efficiency could be increased by adding the oil soluble surfactant with the larger HLB value. Coating with chitosan could considerably increase alcohol resistance.
\end{abstract}

\section{Keywords}

Grape Polyphenol Containing Microcapsules, Palmitic Acid Shell, Chitosan Shell, Spray Drying Method, Layer-by-Layer Method

\footnotetext{
${ }^{*}$ Corresponding author.
}

How to cite this paper: Taguchi, Y., Arakawa, S., Saito, N. and Tanaka, M. (2015) Preparation of Microcapsules Containing Grape Polyphenol with the Spray Drying Method Followed by the Layer-by-Layer Method. Pharmacology \& Pharmacy, 6, 56-64. http://dx.doi.org/10.4236/pp.2015.62008 


\section{Introduction}

Many kinds of microcapsules have been prepared with the chemical and the physicochemical method and applied in various fields such as latent heat storage, cosmetics, foods, drugs, paintings, adhesives, textile, electric materials and so on [1]-[3].

The main functions of microcapsules are to protect the core materials from environment for the desired time, to optionally release the core materials according to appropriate stimuli and to modify the surface of core materials [1]-[3]. The microcapsules with these functions can be prepared by selecting the core and the shell materials with the desired chemical and physicochemical properties and by developing the microencapsulation procedure.

In these microencapsulation methods, the spray drying method has been generally utilized to prepare various powdery composite particles and microcapsules, because the products with stable quality can be continuously manufactured in large quantities [4]-[6]. Furthermore, the spray drying method has a strong point that the various shell materials can be used to prepare the microcapsules [7] [8].

It is well known that grape polyphenol is water-soluble and has a few physiological effects such as anti-aging effect and anti-oxidation effect, but has a few defects such as a bitter taste and reaction activity [9]. Accordingly, if grape polyphenol could be microencapsulated with some edible shell materials and released by appropriate stimulus, it should be expected that the application fields of grape polyphenol will be considerably extended.

Various stimuli-responsive microcapsules for optionally releasing the core material have been applied in many fields such as drug delivery systems (DDS), painting, self-healing agent, cosmetics, foods, and agriculture [2] [3].

As stimuli, mechanical pressure, temperature, water, $\mathrm{pH}$, specified enzyme and ultra violet ray have been utilized according to the physical properties of shell materials.

Among these stimuli, temperature was frequently utilized for controlled release of the core material. As the temperature-responsive shell materials, fatty acids, paraffin wax, fatty acid ester and polymers (poly-N-isopropylacryl-amid) have been applied to form the microcapsule shell. Furthermore, if the thermal responsible shell microcapsules could be coated by another shell material, the microcapsules could be applied in the extensive fields, because the microcapsules could be given another stimuli responsibility.

In this study, it was tried to microencapsulate grape polyphenol with palmitic acid as a hydrophobic shell material by using the spray drying method followed by the layer-by-layer method in order to give alcohol resistance with chitosan shell. The purposes of this study are to prepare the microcapsules containing grape polyphenol with the spray drying method, to coat the microcapsules with chitosan by the layer-by-layer method and to characterize the microcapsules.

\section{Experimental}

\subsection{Materials}

Materials used to prepare the microcapsules containing grape polyphenol were as follows.

Grape polyphenol (GP) (Sunprite Ind. Co., Ltd., Tokyo, Japan) was used as the core material and palmitic acid (PA) (Wako Pure Chemical Ind. Co., Ltd., Tokyo, Japan) was used as the shell material of first microcapsules. Homologue of polyoxyethylene lauryl ether (POEL) with the different HLB values was added as the oil soluble surfactant. The HLB values of POEL were 6.3, 9.6, 11.3. Hereafter, POELs with the HLB values of 6.3, 9.6 and 11.3 are called as POEL(1), POEL(2), POEL(3), respectively. Chitosan (Nacalai Tesque Ind. Co., Ltd., Kyoto, Japan) was used to coat the first microcapsules with the layer-by-layer method. Acetic acid (Wako Pure Chemical Ind. Co., Ltd., Tokyo, Japan) was used to dissolve chitosan.

\subsection{Preparation of Microcapsules}

a) Spray drying method

Figure 1 shows the flow chart for preparing the first microcapsules with the spray drying method, where the spray drying machine equipped with the nozzle of $700 \mu \mathrm{m}$ inner diameter (DL-41: Yamato Science Ind. Co., Tokyo, Japan) was used. The oil solution was prepared by the following two ways.

First, palmitic acid (PA) and grape polyphenol (GP) of a given weight were directly dissolved in ethanol to prepare the oil solution. Second, POEL was dissolved in the oil solution prepared just above in order to stabilize GP and to increase the microencapsulation efficiency. Each oil solution was spray dried by changing the spraying pressure and the inlet temperature to prepare the first microcapsules. Table 1 shows the experimental conditions. 


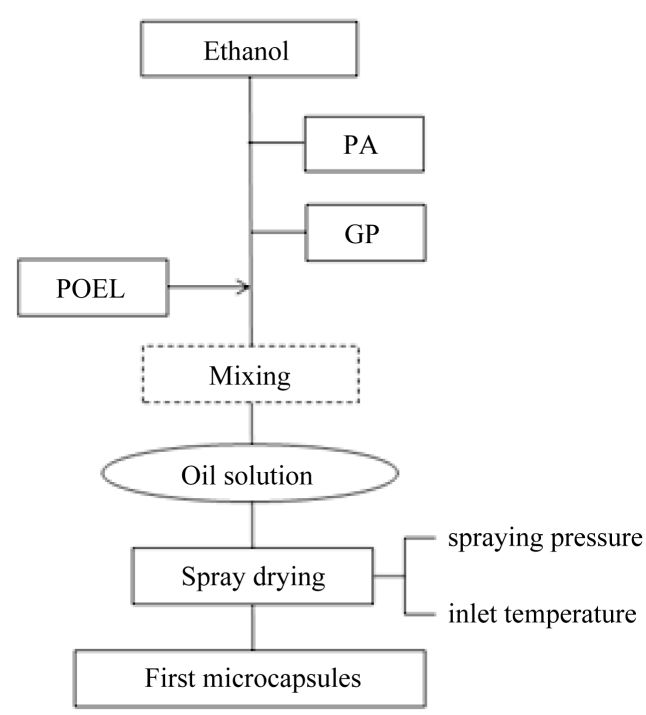

Figure 1. Flow chart for preparing first microcapsules with spray drying.

Table 1. Experimental conditions for preparing first microcapsules.

\begin{tabular}{cc}
\hline Oil solution & \\
\hline Ethanol & $200 \mathrm{ml}$ \\
Palmitic acid (PA) & $10 \mathrm{~g}$ \\
Grape polyphenol (GP) & $2.5 \mathrm{~g}$ \\
Surfactant (POEL) & $1.0 \mathrm{~g}$ \\
HLB of POEL & 6.3: POEL(1), 9.6: POEL(2), 11.3: POEL(3) \\
\hline Spray drying & $0.6 \mathrm{~m}^{3} / \mathrm{min}$ \\
\hline Feed velocity & $\mathrm{P}=0.5,1.0,1.5,2.0 \mathrm{kgf} / \mathrm{cm}^{2}$ \\
Spraying pressure & $\mathrm{T}_{\text {in }}=80,100,120,140^{\circ} \mathrm{C}$ \\
\hline Inlet temperature & \\
\hline
\end{tabular}

b) Layer-by layer method

Figure 2 shows the schematic diagram for preparing the second microcapsules with the layer-by-layer method. Chitosan of a given weight was added into the acetic acid aqueous solution (1 w/vol\%) and dissolved. Then, the first microcapsules of a given weight were added into this acetic acid aqueous solution under stirring due to the magnetic stirrer for $20 \mathrm{~min}$. As chitosan is polycation and the first microcapsules charge negatively, chitosan may adsorb and coat the surface of first microcapsule due to hetero-coagulation. After this operation, the second microcapsules were separated out with filtration paper, dried at room temperature and characterized. The second microcapsules were prepared by changing the chitosan concentration $\left(\mathrm{C}_{\mathrm{s}}\right)$.

Table 2 shows the experimental conditions for preparing the second microcapsules with the layer-by-layer method.

\subsection{Characterization}

Mean diameter and Zeta potential

The mean diameters and Zeta potential of microcapsules were measured by Particle Size Analyzer (SALD3000; Shimazu Seisakusho Ind. Co., Kyoto, Japan). Here, the mean diameters were the Sauter mean diameters.

Yield of microcapsules

The yield (Y) of first microcapsules was obtained by the following Equation (1). 

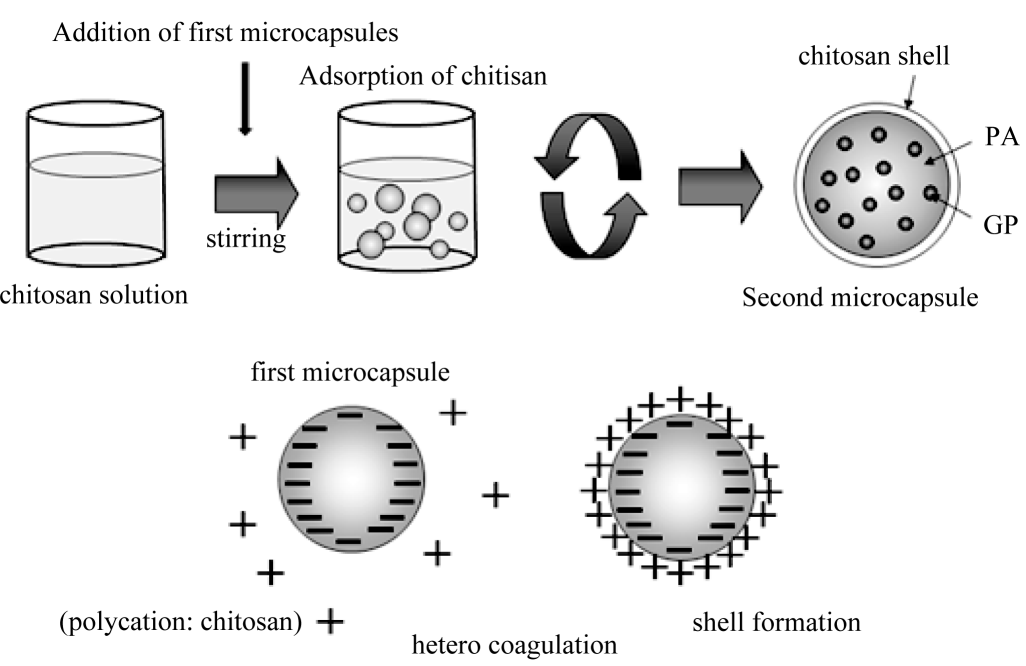

Figure 2. Flow chart for preparing first microcapsules with spray drying.

Table 2. Experimental conditions for preparing second microcapsules.

\begin{tabular}{ll}
\hline Distilled water & \\
\hline Acetic acid & $200 \mathrm{ml}$ \\
First microcapsules & $10 \mathrm{~g}$ \\
Chitosan & $\mathrm{C}_{\mathrm{S}}=1.0 \mathrm{~g}(1.0 \mathrm{w} / \mathrm{v} \%), 2.0 \mathrm{~g}(2.0 \mathrm{w} / \mathrm{v} \%), 3.0 \mathrm{~g}(3.0 \mathrm{w} / \mathrm{v} \%)$ \\
Stirring velocity & $1.0 \mathrm{~g}$ \\
Microencapsulation time & 6.3: POEL(1), 9.6: POEL(2), 11.3: POEL(3) \\
\hline
\end{tabular}

$$
\mathrm{Y}=\frac{\text { weight of microcpsules collected }}{\text { weight of }(\mathrm{GP}+\mathrm{PA}+\mathrm{POEL})} \times 100
$$

Microencapsulation efficiency

The microencapsulation efficiency $(\lambda)$ was measured as follows. The first microcapsules of a given weight were added into distilled water and stirred by the magnetic stirrer for $10 \mathrm{~min}$ in order to dissolve the unmicroencapsulated GP. Then, the microcapsules washed with distilled water were added into distilled water of $100 \mathrm{~cm}^{3}$ and broken by the rotor stator homogenizer under the conditions of stirring velocity of $2000 \mathrm{rpm}$ for $10 \mathrm{~min}$. Furthermore, the microcapsule slurry prepared just above was stirred by the ultrasonic homogenizer for 10min in order to perfectly dissolve GP in water. The concentration of GP in water was measured by the absorption spectrophotometer (UV-160A, Shimazu Seisakusho, Ind. Co., Kyoto, Japan). For this measurement, the calibration curve between the concentration of GP and the absorption degree was obtained beforehand. Then, the microencapsulation efficiency $(\lambda)$ was calculated by the following Equation (2).

$$
\lambda=\frac{\text { weight of GP measured }}{\text { weight of GP in feed }} \times 100
$$

Alcohol resistance

The second microcapsules of a given weight were added in ethylalcohol under stirring due to the magnetic stirrer. Then, the photographs of second microcapsules were taken by the optical microscope at the constant time intervals.

The transient mean diameters of microcapsules were measured from these photographs. Then, the alcohol solution was sampled out and the concentration of GP was measured by the same method as stated above.

Observation

The microcapsules were observed by scanning electron microscope (SEM: JSM-5800) and optical microscope (DP10, OLYMPUS Ind. Co., Ltd., Tokyo, Japan). 


\section{Results and Discussion}

\subsection{Effects of Spraying Pressure and Inlet Temperature}

Figure 3 shows the SEM photographs of first microcapsules prepared by changing the spraying pressure (a) and the inlet temperature (b). The spherical and irregular microcapsules with the wider diameter distributions are observed. The diameters of microcapsules decreased with the spraying pressure $(\mathrm{P})$ and increased with the inlet temperature $\left(\mathrm{T}_{\text {in }}\right)$.

In order to know the dependence of mean diameters on the spraying conditions in detail, the dependences of mean diameters and standard deviations of microcapsules on the spraying pressure $(\mathrm{P})$ and the inlet temperature $\left(\mathrm{T}_{\mathrm{in}}\right)$ are shown in Figure 4. With increasing the spraying pressure, the mean diameters drastically decreased

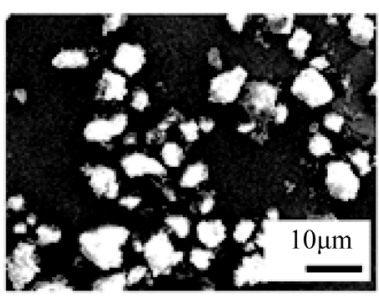

$P=0.5\left[\mathrm{kgf} / \mathrm{cm}^{2}\right]$

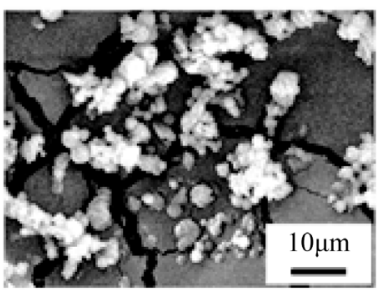

$\mathrm{P}=1.5\left[\mathrm{kgf} / \mathrm{cm}^{2}\right]$

$\mathrm{T}_{\text {in }}=100\left[{ }^{\circ} \mathrm{C}\right]$

(a)

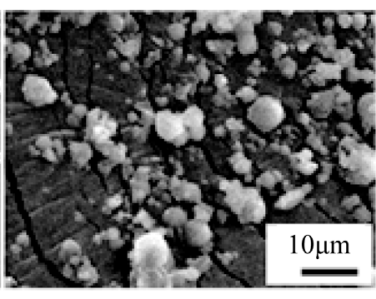

$P=1.0\left[\mathrm{kgf} / \mathrm{cm}^{2}\right]$

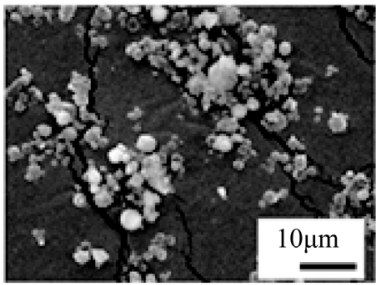

$P=2.0\left[\mathrm{kgf} / \mathrm{cm}^{2}\right]$

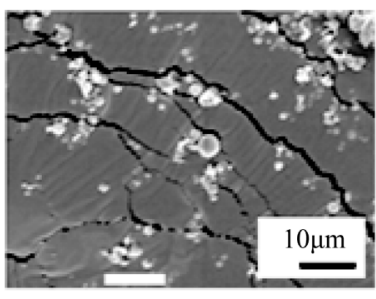

$\mathrm{T}_{\mathrm{in}}=80\left[{ }^{\circ} \mathrm{C}\right]$

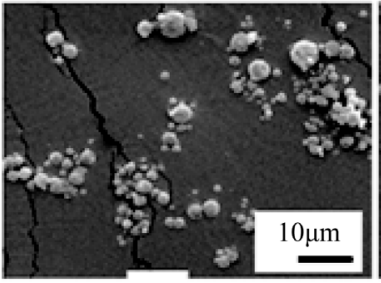

$\mathrm{T}_{\mathrm{in}}=120\left[{ }^{\circ} \mathrm{C}\right]$

(b)

$\mathrm{T}_{\text {in }}=140\left[{ }^{\circ} \mathrm{C}\right]$

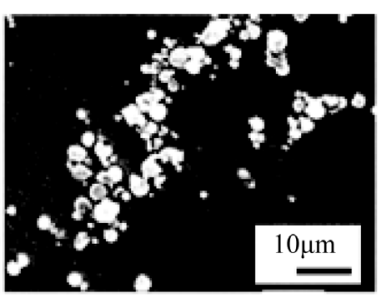

$\mathrm{T}_{\text {in }}=100\left[{ }^{\circ} \mathrm{C}\right]$

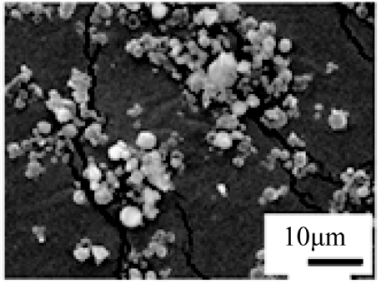

Figure 3. SEM photographs of microcapsules (effects of spraying pressure (a) and inlet temperature (b)).

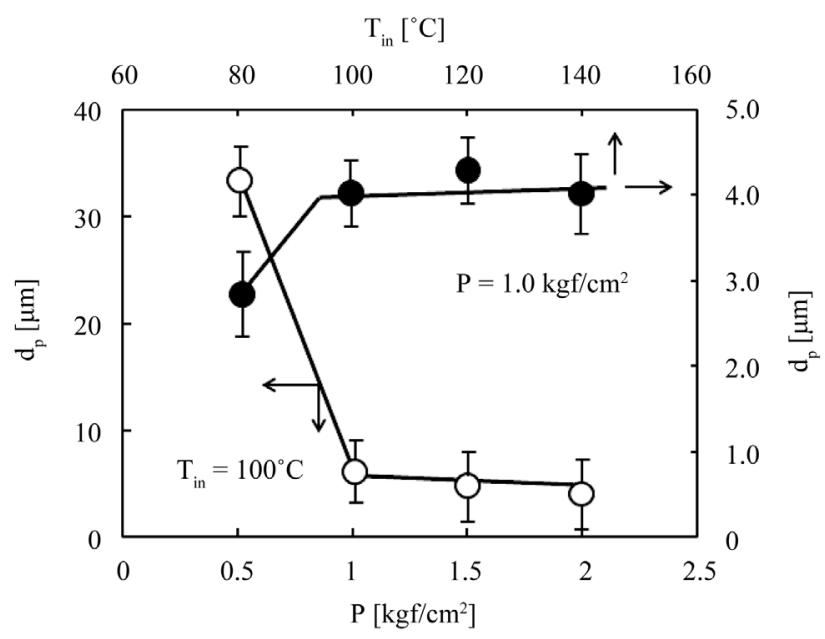

Figure 4. Dependences of mean diameters and standard deviation on spraying pressure and inlet temperature. 
from $35 \mu \mathrm{m}$ at $\mathrm{P}=0.5 \mathrm{kgf} / \mathrm{cm}^{2}$ to $5 \mu \mathrm{m}$ at $\mathrm{P}=1.0 \mathrm{kgf} / \mathrm{cm}^{2}$ and then gradually decreased. While, with increasing the inlet temperature, the mean diameters slightly increased from $3.2 \mu \mathrm{m}$ at $\mathrm{T}_{\text {in }}=80^{\circ} \mathrm{C}$ to $4.5 \mu \mathrm{m}$ at $\mathrm{T}_{\text {in }}=100^{\circ} \mathrm{C}$ and then kept almost constant. Also, as the dispersion degree (standard deviation/mean diameter) changed from 0.3 to 0.65 , the diameter distributions were found to be wider. The higher the inlet temperature, the faster the evaporation speed of ethanol and the faster the preparation of microcapsules. However, the volcanic phenomenon on the surface of oil droplets may occur due to fast evaporation, leading to the unstability of oil droplets [10]. As a result, the first microcapsules may become easy to adhere or coalesce and the diameters of microcapsules may become larger.

Figure 5 and Figure 6 show the effects of spraying pressure and inlet temperature on the yield (Y) and the microencapsulation efficiency $(\lambda)$, respectively. With increasing the spraying pressure, the yield and the microencapsulation efficiency increased from $\mathrm{Y}=15 \%$ at $\mathrm{P}=0.5 \mathrm{kgf} / \mathrm{cm}^{2}$ to $\mathrm{Y}=55 \%$ at $\mathrm{P}=2.0 \mathrm{kgf} / \mathrm{cm}^{2}$ and from $\lambda=$ $7 \%$ at $\mathrm{P}=0.5 \mathrm{kgf} / \mathrm{cm}^{2}$ to $\lambda=75 \%$ at $\mathrm{P}=2.0 \mathrm{kgf} / \mathrm{cm}^{2}$, respectively.

On the other hand, with increasing the inlet temperature, the yield $(\mathrm{Y})$ and the microencapsulation efficiency ( $\lambda$ ) increased from $\mathrm{Y}=8 \%$ at $\mathrm{T}_{\text {in }}=80^{\circ} \mathrm{C}$ to $\mathrm{Y}=56 \%$ at $\mathrm{T}_{\text {in }}=140^{\circ} \mathrm{C}$ and $\lambda=60 \%$ at $\mathrm{T}_{\text {in }}=80^{\circ} \mathrm{C}$ to $\lambda=75 \%$ at $\mathrm{T}_{\text {in }}$ $=140^{\circ} \mathrm{C}$, respectively. When the inlet temperature and the spray drying pressure are lower, the sound oil droplets may not be prepared through the nozzle because of higher viscosity of oil solution.

Also, as the diameters of first microcapsules become larger at the low spraying pressure of $P=0.5 \mathrm{kgf} / \mathrm{cm}^{2}$, the yield and the microencapsulation efficiency may become lower because of the insufficient drying at the lower inlet temperature.

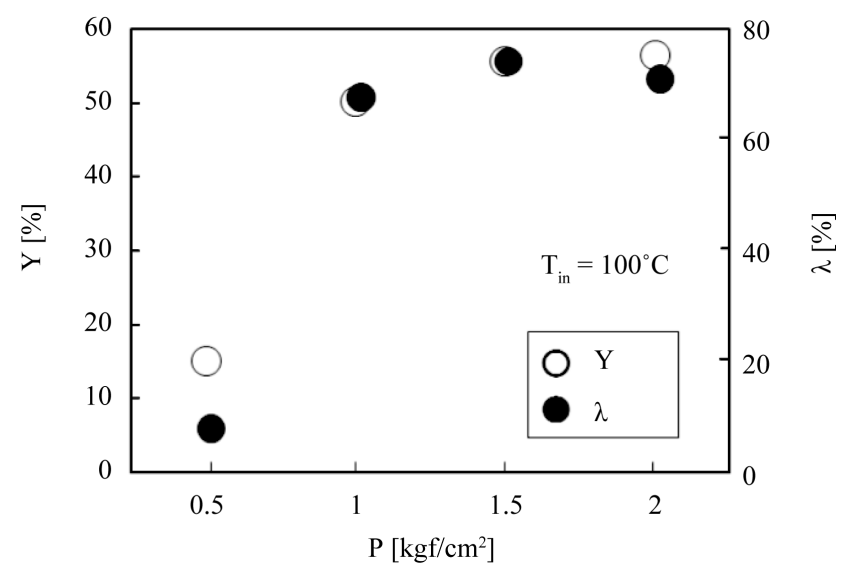

Figure 5. Effect of spraying pressure on yield and microencapsulation efficiency.

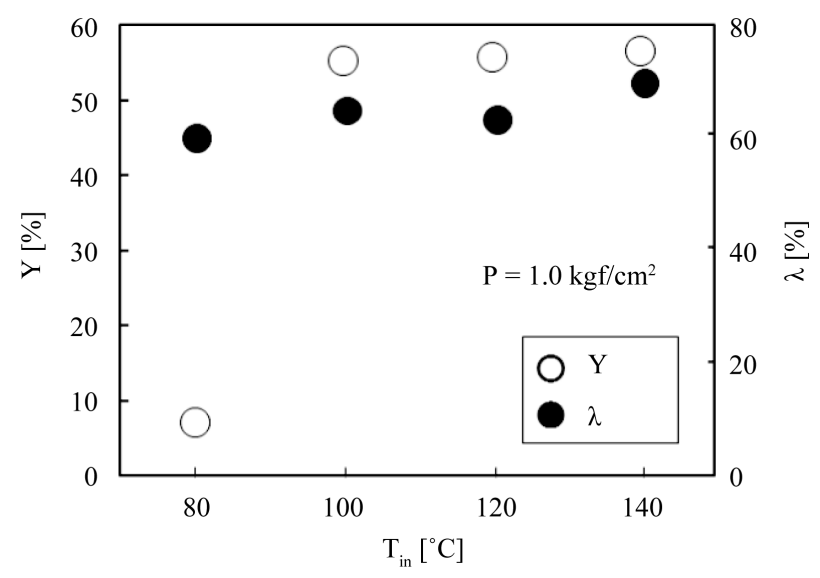

Figure 6. Effect of inlet temperature on yield and microencapsulation efficiency. 


\subsection{Effect of Addition of Oil Soluble Surfactant}

As the low microencapsulation efficiencies were obtained, the oil soluble surfactants with the different HLB values were added to stabilize GP in the oil solution. The effect of oil soluble surfactants on the mean diameters, the yield and the microencapsulation efficiency of microcapsules were investigated, where the first microcapsules were prepared at $\mathrm{P}=1.5 \mathrm{kgf} / \mathrm{cm}^{2}$ and $\mathrm{T}_{\text {in }}=100^{\circ} \mathrm{C}$.

Figure 7 shows the dependencies of the yield, the microencapsulation efficiency and the mean diameters on the oil surfactant species. From Figure 7, the following fundamental informations could be obtained. The mean diameters slightly decreased by addition of oil soluble surfactant, but the difference in the mean diameters due to the surfactant species was not clear. And, the diameter distributions become narrower than without the surfactant. The yield increased from $\mathrm{Y}=55 \%$ without the surfactant to $\mathrm{Y}=72 \%$ with POEL(3). The microcapsulation efficiency increased $\lambda=75 \%$ without the surfactant to $\lambda=92 \%$ with POEL(3). Increase in the microencapsulation efficiency may be due to increase in the stability of GP in the oil solution. Namely, GP might be stabilized with the wrapping effect due to the hydrophilic group of oil soluble surfactant [11] [12]. As the hydrophilic group of POEL(3) is larger than those of POEL(1) and POEL(2), the stabilization of GP due to the wrapping effect may become stronger.

\subsection{Alcohol Resistance}

As, generally, the microcapsules prepared by the spray drying were multi core type, it can be expected that the core materials are on the surface of microcapsules [5]-[7]. If the core materials were on the surface of microcapsules, the core materials could not be prevented the microcapsules from contacting with circumstance. In order to solve these troubles, the emulsions were stabilized by adding some surfactants and proteins [4] [7] [8] [13]. Similarly, in this study, the first microcapsules prepared by the spray drying method were coated with the layer-by-layer method.

Namely, in order to give the microcapsules alcohol resistance, the first microcapsules were coated with chitosan by the layer-by-layer method.

Figure 8 shows the optical microscopic photographs of the transient features of first microcapsules (a) and the second microcapsules (b). It was found that the first microcapsules disappeared at $60 \mathrm{~min}$, but the second microcapsules could be observed even at $48 \mathrm{~h}$.

Also, Figure 9 shows the transient features of the ratios $\left(\mathrm{d}_{\mathrm{pt}} / \mathrm{d}_{\mathrm{po}}\right)$ of mean diameters, where $\mathrm{d}_{\mathrm{po}}$ and $\mathrm{d}_{\mathrm{pt}}$ are the mean diameters at $\mathrm{t}=0$ and $\mathrm{t}=\mathrm{t}$ from adding the second microcapsules in ethyl alcohol, respectively. In Figure $9, \mathrm{~d}_{\mathrm{pt}} / \mathrm{d}_{\mathrm{po}}=1$ means that the microcapsules in ethyl alcohol are kept without dissolution. Also, the smaller the values of ratios, the lower the alcohol resistance because of dissolution of microcapsules. The first microcapsules rapidly dissolved in ethanol and disappeared at ca. 1h. Meanwhile, the second microcapsules coated with the chitosan concentration $\left(\mathrm{C}_{\mathrm{s}}\right)$ of $1.0 \mathrm{w} / \mathrm{v} \%$ gradually dissolved with elapsing time. However, the second microcapsules coated with the chitosan concentration $\left(\mathrm{C}_{\mathrm{S}}\right)$ of $2.0 \mathrm{w} / \mathrm{v} \%$ and $3.0 \mathrm{w} / \mathrm{v} \%$ did not dissolve and remained even at $48 \mathrm{~h}$.

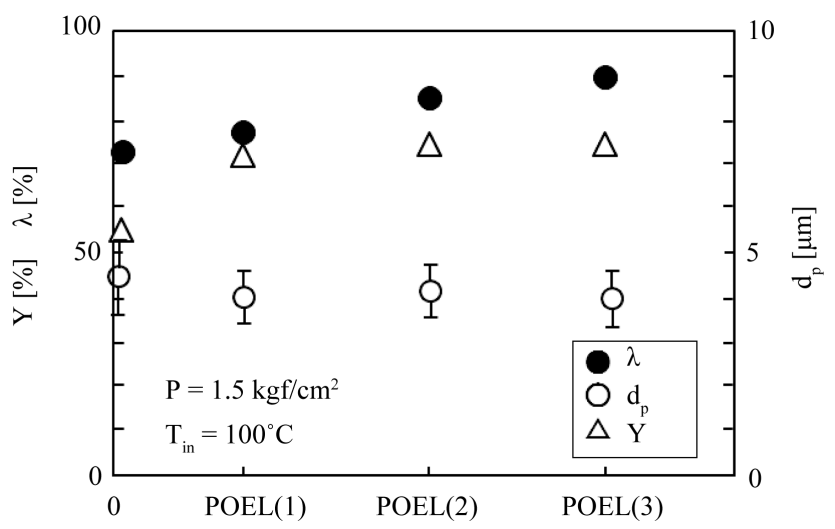

Figure 7. Dependences of microencapsulation efficiency, yield and mean diameter on oil soluble surfactant species. 


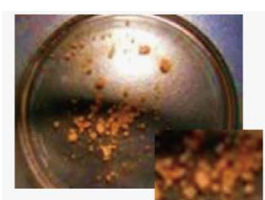

0 min

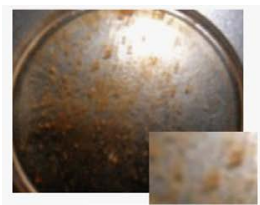

$0 \mathrm{~min}$

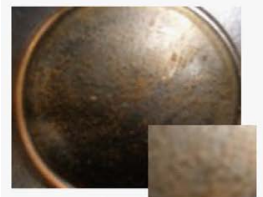

$6 h$

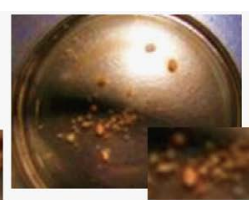

$10 \mathrm{~min}$

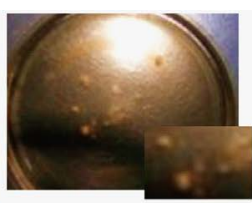

$30 \mathrm{~min}$

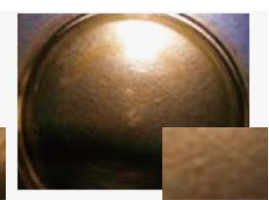

$60 \mathrm{~min}$

(a)

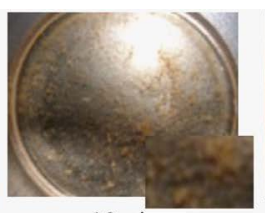

$10 \mathrm{~min}$

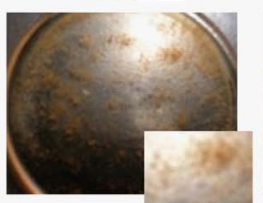

$12 \mathrm{~h}$

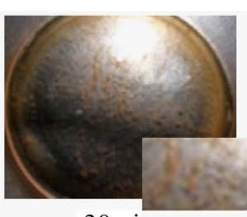

$30 \mathrm{~min}$

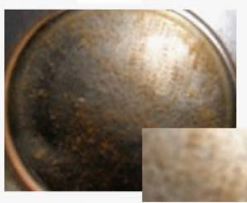

$24 \mathrm{~h}$

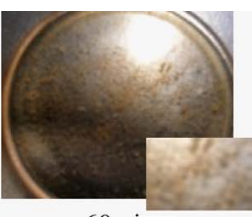

$60 \mathrm{~min}$

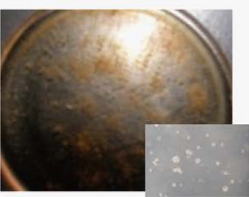

$48 \mathrm{~h}$

(b)

Figure 8. Observation of microcapsules in ethanol. (a) First microcapsules; (b) Second microcapsules ( $2.0 \mathrm{w} / \mathrm{v} \%$ of chitosan concentration).

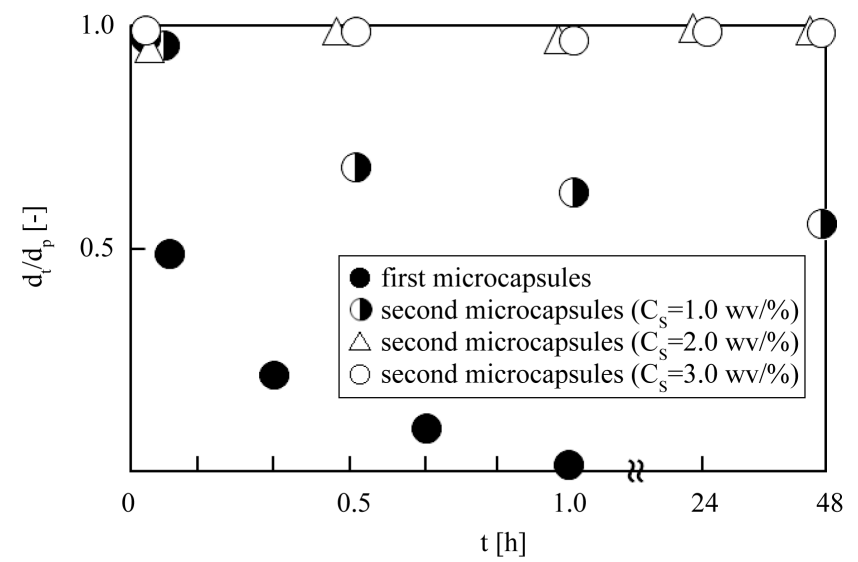

Figure 9. Transient features of ratios of mean diameters of microcapsules.

From these results it was confirmed that the second microcapsules were given alcohol resistance by the chitosan coating. The first microcapsules have the negative surface charge $(-5.3 \mathrm{mV})$ due to the carboxylic group and chitosan is polycation. As a result, chitosan may adsorb on the surface of first microcapsules to form the chitosan shell with alcohol resistance.

\section{Conclusions}

The palmitic acid microcapsules containing grape polyphenol were prepared with the spray drying method followed by the layer-by-layer method using chitosan. The following fundamental results could be obtained.

1) The microcapsules with the mean diameters from $5 \mu \mathrm{m}$ to $35 \mu \mathrm{m}$ could be prepared by changing the spraying pressure and the inlet temperature.

2) The yield and the microencapsulation efficiency could be increased by increasing the spraying pressure and the inlet temperature.

3) The yield and the microencapsulation efficiency could be considerably increased by the addition of oil so- 
luble surfactant.

4) The larger the HLA values, the higher the microencapsulation efficiency due to the wrapping effect.

5) The second microcapsules could be given alcohol resistance by chitosan coating.

\section{References}

[1] Tanaka, M. (2008) Key Point of Preparation of Nano/Microcapsules. Techno System Publishing Co. Ltd., Tokyo.

[2] Kondo, T. (1967) Saishin Maikurokapseruka Gijutsu (Microencapsulation Technique). TES, Tokyo.

[3] Koishi, M., Eto, K. and Higure, H. (2005) (Preparation + Utilization) Microcapsules. Kogyo Chosakai, Tokyo.

[4] Shirokawa, K., Taguchi, Y., Yokoyama, H., Ono, F. and Tanaka, M. (2013) Preparation of Temperature and Water Responsive Microcapsules Containing Hydroquinone with Spray Drying Method. Journal of Cosmetics, Dermatological Sciences and Applications, 3, 49-54. http://dx.doi.org/10.4236/jcdsa.2013.33A2012

[5] Soottitantawat, A., Bigeard, F., Uoshii, H., Furuta, T., Ohkawara, A. and Linko, P. (2005) Influence of Emulsion and Powder Size on the Stability of Encapsulated D-Limonene by Spray Drying. Innovative Food Science and Emerging Technologies, 6, 107-114. http://dx.doi.org/10.1016/j.ifset.2004.09.003

[6] Polavarapu, S., Oliver, C.M., Ajlouni, S. and Augustin, M.A. (2012) Impact of Extra Virgin Olive Oil and Ethylenediaminetetraacetic Acid (EDTA) on the Oxidative Stability of Fish Oil Emulsions and Spray-Dried Microcapsules Stabilized by Sugar Beet Pectin. Journal of Agricultural and Food Chemistry, 60, 444-450. http://dx.doi.org/10.1021/jf2034785

[7] Laohasongkram, K., Mahamaktudsanee, T. and Chaiwanichsiri, S. (2011) Microencapsulation of Macadamia Oil by Spray Drying. Procedia Food Science, 1, 1660-1665. http://dx.doi.org/10.1016/j.profoo.2011.09.245

[8] Gharsallaoui, A., Roudaut, G., Beney, L., Chambin, O., Voilley A. and Saurel, R. (2012) Properties of Spray-Dried Food Flavours Microencapsulated with Two-Layered Membranes: Roles of Interfacial Interactions and Water. Food Chemistry, 132, 1713-1720. http://dx.doi.org/10.1016/j.foodchem.2011.03.028

[9] Xia, E.Q., Deng, G.F., Guo, Y.J. and Li, H.B. (2010) Biological Activities of Polyphenols from Grapes. International Journal of Molecular Sciences, 11, 622-646. http://dx.doi.org/10.3390/ijms11020622

[10] Yokoyama, H., Mo, L., Taguchi, Y. and Tanaka, M. (2008) Effect of Viscosity of Shell Solution on the Content of Solid Powder as Core Material in Microencapsulation by the Drying-in-Liquid Method. Journal of Applied Polymer Science, 109, 1585-1593. http://dx.doi.org/10.1002/app.24765

[11] Kobayashi, S., Taguchi, Y. and Tanaka, M. (2005) Preparation of Nanospheres Containing Dye by Mini Emulsion Polymerization. Journal of the Japan Society of Colour Material, 78, 260-264. http://dx.doi.org/10.4011/shikizai1937.78.260

[12] Erdem, B., Sudol, E.D., Dimonie, V.L. and El-Aasser, M.S. (2000) Encapsulation of Inorganic Particles via Miniemulsion Polymerization. Macromolecular Symposia, 155, 181-198. http://dx.doi.org/10.1002/1521-3900(200004)155:1<181::AID-MASY181>3.0.CO;2-2

[13] Gharsallaoui, A., Saurel, R., Chambin, O., Cases, E., Voilley, A. and Cayot, P. (2010) Utilisation of Pectin Coating to Enhance Spray-Dry Stability of Pea Protein-Stabilised Oil-in-Water Emulsions. Food Chemistry, 122, 447-454. http://dx.doi.org/10.1016/j.foodchem.2009.04.017 
Scientific Research Publishing (SCIRP) is one of the largest Open Access journal publishers. It is currently publishing more than 200 open access, online, peer-reviewed journals covering a wide range of academic disciplines. SCIRP serves the worldwide academic communities and contributes to the progress and application of science with its publication.

Other selected journals from SCIRP are listed as below. Submit your manuscript to us via either submit@scirp.org or Online Submission Portal.
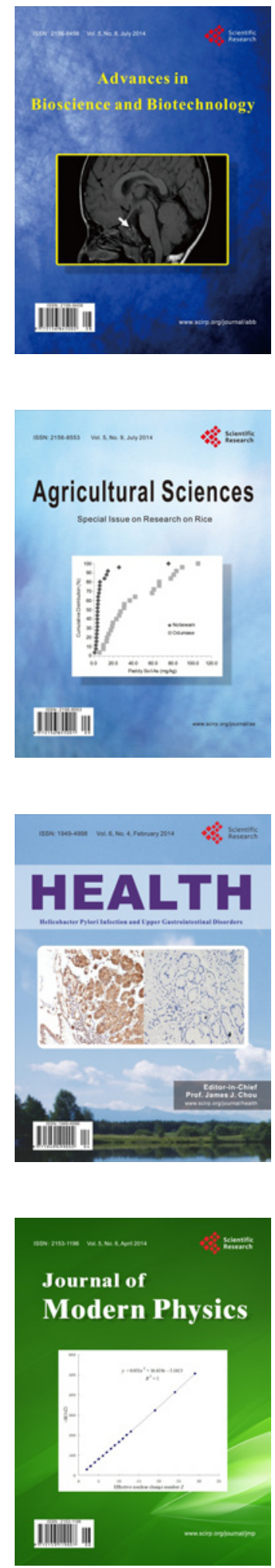
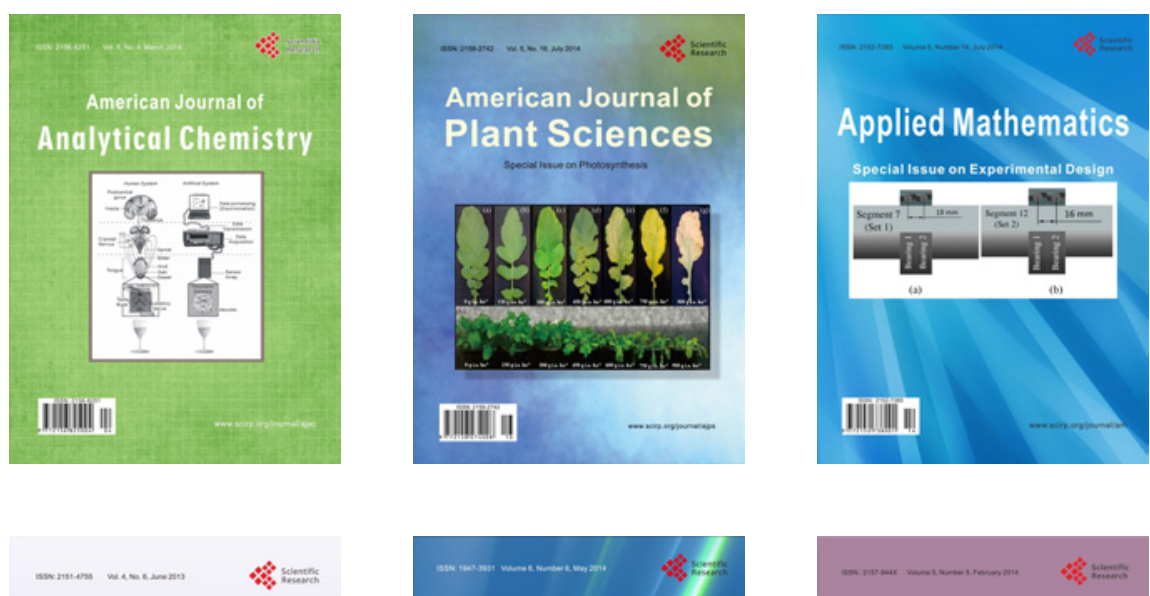

Creative Education
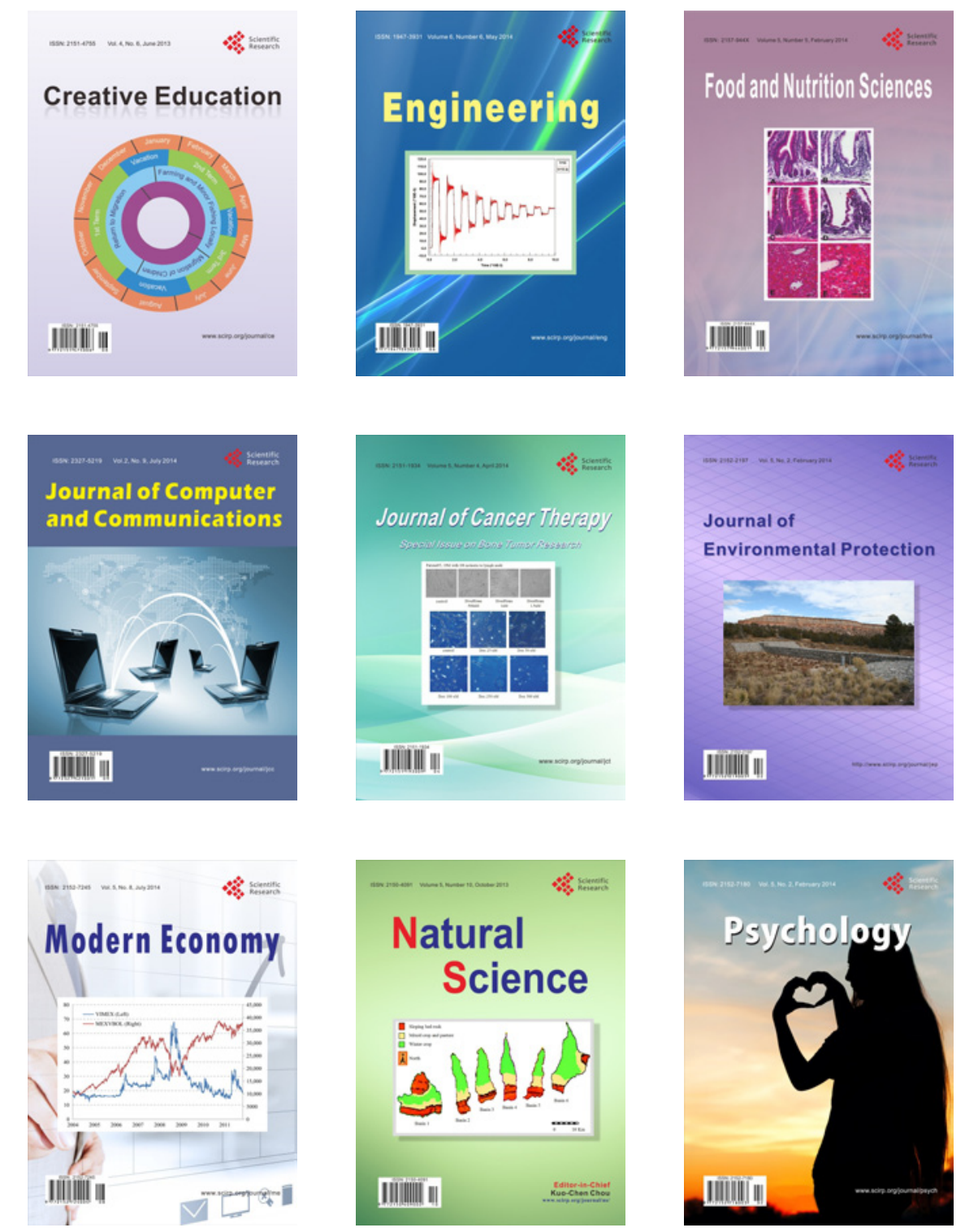